\title{
University of Kentucky Rural Physician Leadership Program: \\ A Programmatic Review
}

\author{
Paula K Arnett; Terry Stratton; Anthony Weaver; Carol Elam
}

\section{Abstract}

This article describes the characteristics and results of the Rural Physician Leadership Program (RPLP) at the University of Kentucky College of Medicine. RPLP is a successful example of a regional medical campus designed to train physicians at a regional medical campus to serve rural areas through local partnerships.

While producing adequate numbers of health care providers is critical to ensuring accessibility, persistent maldistributions away from certain areas have created chronic, geographic pockets of medical underservice across the U.S. As a case in point, a recent workforce report by the Kentucky Institute of Medicine, titled Quality Through Collaboration: The Future of Rural Health Care, found that only $30 \%$ of physicians currently practice in rural areas across Kentucky ${ }^{1}$, despite $42 \%$ of the state's population residing in such areas. ${ }^{2}$ To address these shortages strategically, the report recommended expanding the medical school applicant pool to select and train more students from rural and other underserved areas. In addition to recruitment, it was further suggested by a consortium of rural health scholars that medical schools "locate a meaningful portion of the educational experience in rural communities". 3 (Page 10)

Many states with significant rural populations have medical education programs designed to bolster the supply of physicians in these areas, ${ }^{4-9}$ and recruiting students most amenable to establishing practices in such regions is key to the success of these efforts.

Recognizing that the pipeline to eventual medical practice begins early, the University of Kentucky College of Medicine (UKCOM) developed the Rural Physician Leadership Program (RPLP) in 2008 to address the state's persistent and growing need for rural physicians. A collaborative effort partnering the UKCOM in Lexington, St. Claire Regional Medical Center, and Morehead State University, the RPLP is administered at the Center for Health Education and Research in Morehead, Kentucky - a community of about 7,000 located in west-central Appalachia. The goal of the RPLP is to identify and train physicians of all specialties to serve as both medical practitioners and community advocates in rural Kentucky. Toward this end, graduates gain the knowledge and experience necessary to impact health at both individual patient and community levels. This paper provides an overview of this initiative, which is now in its eighth year, by describing the approach to recruitment and admissions as well as curriculum and special educational initiatives, and providing outcome data related to student performance and residency choice.

Recruitment and Admissions

RPLP recruitment is strategically focused on attracting applicants with a sincere desire to work in rural Kentucky. Both the RPLP Assistant Dean and the UKCOM Associate Dean for Admissions and Institutional Advancement routinely tout the program to premedical groups at colleges and universities across the state. Other initiatives include meetings with premedical students at events hosted by Kentucky's Area Health Education Centers, the Kentucky Rural Health Association, and the University of Kentucky Professional Education Preparation Program. Additionally, RPLP faculty and staff host open houses throughout the year for prospective students and their families to visit Morehead, speak with teaching faculty, administrators, and current medical students, and tour instructional and clinical facilities. In 2014, RPLP staff initiated an intensive four-day Medical School Admissions Boot Camp for junior and senior undergraduates interested in medical careers. The program prepared rural students from smaller colleges and regional universities in Kentucky for the medical school admissions process by providing application reviews, Medical College Admission

Paula K Arnett, DrPH, MBA; Associate Dean for Administration; University of Kentucky College of Public Health

Terry Stratton, PhD; Assistant Dean, Assessment \& Quality Management; Office of Medical Education; University of Kentucky College of Medicine

Anthony Weaver, MD; Assistant Dean, Rural Physician Leadership Program; University of Kentucky College of Medicine Carol Elam, PhD; Associate Dean for Admissions and Institutional Advancement; Office of Medical Education ; University of Kentucky College of Medicine

Corresponding author: Paula K Arnett, DrPH, MBA; Associate Dean for Administration; University of Kentucky College of Public Health; 111 Washington Avenue, Suite 212 Lexington, KY 40351; (859) 323-7020 office (606) 783-5063 fax; paula.arnett@uky.edu 
Test practice examinations, and mock interview sessions.

To select the most qualified and desirable applicants, the RPLP maintains a distinct but parallel admissions process with the regular MD program at UKCOM. Students interested in the RPLP merely designate 'other special programs' on their American Medical College Application Service (AMCAS) application and a supplemental UKCOM form. From those screened, selected RPLP applicants are invited for personal interviews in both Morehead and Lexington. Clinical faculty members, regional university faculty, medical center administrators, and key community members comprise the RPLP interviewers in Morehead - after which applicants complete a 'traditional' interview with UKCOM interviewers in Lexington. After a holistic review of candidates' interests, experiences, and qualifications, the UKCOM Admissions Committee, with RPLP input, admits about 10 students annually into the program.

\section{Curriculum}

RPLP students complete all required preclinical (M1-M2) coursework at the main campus academic medical center (AMC) in Lexington. During this time, RPLP students are kept together for small group learning activities whenever possible. Introduction to the Medical Profession, a first-year 'doctoring' course, includes RPLP faculty who broach topics such as medical ethics, professionalism, health care disparities, and sociocultural aspects of health care from a rural health perspective.

Between the M1-M2 years, RPLP students experience patient care outside of the large AMC during the two-week RPLP Clinical Preparation Summer Experience at St. Claire Regional Medical Center. There, they interview patients, take vital signs, write notes, and make clinical presentations alongside community preceptors and third-year RPLP students. During year two, they meet weekly with the RPLP Assistant Dean to discuss rural-related topics in an elective course.

Third-year clinical training signals a curricular departure from the traditional MD pathway at UKCOM. Based at St. Claire Regional Medical Center and other regional sites, RPLP students complete core clerkships in family and community medicine, internal medicine, emergency medicine, surgery, obstetrics and gynecology, pediatrics, neurology, and psychiatry, but with a more individualized focus on rural populations.

The final year of undergraduate training allows students to further develop and demonstrate their clinical skills and to prepare for residency in their chosen specialty. Recognizing that different specialties may have different emphases, the fourth-year curriculum allows students to select rotations that are integral to their future careers. As a result, RPLP students can take their two required Acting Internships at St. Claire Regional Medical Center or at the University of Kentucky.
Similarly, RPLP students may complete some or all of five clerkship electives in Morehead, Lexington, or elsewhere.

Curricular Innovations

The RPLP boasts three curricular hallmarks: 1) A longitudinal family medicine experience; 2 ) a business education and leadership certificate program; and 3) a community engagement/intervention project. In the longitudinal experience, students staff a weekly clinic throughout the entire third year, which provides them familiarity with the clinic workings, continuity of care, and community immersion. Students observe firsthand the benefits of long-term doctor-patient relationships and the practicalities of running a medical practice. Interactions with the local health department, first responders, pharmacies, home health, nursing homes, home medical equipment suppliers, podiatry clinics, and pain specialists allow students to experience and participate in true inter-professional patient care.

In collaboration with the Morehead State University College of Business and Public Affairs, RPLP students are enrolled in a business education and leadership certificate program. Utilizing an executive training modular format for instruction and learning, topics addressed include recent changes in healthcare policy and law, financing, payment systems, and insurance, electronic health records and mobile technology to monitor personal health status, and ethical dilemmas in healthcare and public health advocacy. Other key topics addressed include strategic planning and organizational management.

Because the connectedness of community involvement can improve the recruitment and retention of rural medical professionals, ${ }^{11-12}$ community engagement activities form an integral part of the RPLP program. Students work with various Morehead community leaders, providers, and agencies, including the Mayor, Chamber of Commerce members, legislators, local health department providers, dentists, pharmacists, podiatrists, first responders, and school health nurses. As part of this experience, RPLP students have provided health education to community schools, developed and presented wellness programs for local businesses, and participated in community health fairs.

During their fourth year of medical school, RPLP students complete a project involving research, quality improvement, or community engagement which they present each spring at the St. Claire Regional Research Day program. Examples of past projects are presented in Table 1. 
Table 1. RPLP Community Engagement Projects

\begin{tabular}{|l|l|}
\hline \multicolumn{1}{|c|}{ Title } & \multicolumn{1}{c|}{ Description } \\
\hline $\begin{array}{l}\text { "Lifestyle Predictors of } \\
\text { Eastern Kentucky" }\end{array}$ & $\begin{array}{l}\text { Over two years, students } \\
\text { conducted a randomized, } \\
\text { cross-sectional study of } \\
\text { families attending a community } \\
\text { health event. Parents were } \\
\text { asked to provide height and } \\
\text { weight of their oldest child. }\end{array}$ \\
\hline $\begin{array}{l}\text { "Outreach Event } \\
\text { Self Efficacy in }\end{array}$ & $\begin{array}{l}\text { Students created the "Spread } \\
\text { The Love-a-thon" outreach } \\
\text { Health Issues" } \\
\text { event to combat suicidal } \\
\text { behavior. During this annual } \\
\text { event, teens use their own cell } \\
\text { phones and laptops to send } \\
\text { complimentary 'Lifelines' to } \\
\text { friends and family. }\end{array}$ \\
\hline $\begin{array}{l}\text { "Blue in the Bluegrass: } \\
\text { Examining Kentucky's } \\
\text { Elevated Depression } \\
\text { Rates" }\end{array}$ & $\begin{array}{l}\text { Using existing data, research } \\
\text { was conducted on the } \\
\text { relationship among depression, } \\
\text { religion, alcohol use, and } \\
\text { education. }\end{array}$ \\
\hline $\begin{array}{l}\text { "Evaluation Of } \\
\text { Developing a Student } \\
\text { Run Free Clinic in } \\
\text { Morehead, Kentucky" }\end{array}$ & $\begin{array}{l}\text { With recent changes in } \\
\text { insurance availability, students } \\
\text { conducted a needs assessment } \\
\text { at the Morehead free clinic for } \\
\text { a possible student run } \\
\text { supplement. Students } \\
\text { subsequently developed a } \\
\text { Community Health Interest } \\
\text { Group to provide education } \\
\text { and other services to the larger } \\
\text { community. }\end{array}$ \\
\hline
\end{tabular}

\section{Outcomes}

Recruitment and Admissions

Since its inception in 2009, the annual number of RPLP applications ranged from 25 to 61 , resulting in 363 total applications and 79 matriculants (see Table 2). The average Medical College Admission Test (MCAT) score (range 1-45) and cumulative grade point average (GPA) of students enrolled in the RPLP program was 29.0 and 3.7, respectively. Applicants came from 21 different Kentucky colleges or universities, predominantly the University of Kentucky (35.9\%) and Morehead State University (19.2\%). Of the 78 matriculating RPLP students, 46 (59.0\%) hailed from Appalachian counties ${ }^{10}$ and 14 (17.9\%) from other rural areas of the state, including six from Western Kentucky. To date, $19.2 \%$ (15) of students matriculating in the RPLP have been from out of state.
Table 2. RPLP Applicants and Matriculating Students: GPA and MCAT Averages

\begin{tabular}{|c|c|c|c|c|c|c}
\hline $\begin{array}{c}\text { Year } \\
\text { Admitted }\end{array}$ & $\begin{array}{c}\text { Total } \\
\text { Applications }\end{array}$ & $\begin{array}{c}\text { Matriculating } \\
\text { Students }\end{array}$ & $\begin{array}{c}\text { Applicant } \\
\text { Average } \\
\text { GPA }\end{array}$ & $\begin{array}{c}\text { Matriculating } \\
\text { Students: } \\
\text { Average GPA }\end{array}$ & $\begin{array}{c}\text { Applicants: } \\
\text { Average } \\
\text { MCAT }\end{array}$ & $\begin{array}{c}\text { Matriculating } \\
\text { Students: } \\
\text { Average } \\
\text { MCAT }\end{array}$ \\
\hline 2009 & 43 & 8 & 3.5 & 3.8 & 25.0 & 28.9 \\
\hline 2010 & 26 & 9 & 3.6 & 3.7 & 26.0 & 27.1 \\
\hline 2011 & 61 & 10 & 3.6 & 3.8 & 25.3 & 28.0 \\
\hline 2012 & 25 & 10 & 3.6 & 3.7 & 26.6 & 28.1 \\
\hline 2013 & 61 & 11 & 3.7 & 3.8 & 25.9 & 29.7 \\
\hline 2014 & 60 & 10 & 3.5 & 3.6 & 26.6 & 30.8 \\
\hline 2015 & 42 & 10 & 3.6 & 3.7 & 27.0 & 30.5 \\
\hline 2016 & 45 & 11 & 3.7 & 3.8 & $26.8 *$ & $28.9 *$ \\
\hline 2015 \\
\hline
\end{tabular}

Below, Table 3 lists RPLP matriculants' average scores on Steps 1 and 2 of the required United States Medical Licensure Exams (USMLE). Pass rates for firsttime test takers has consistently been at or above the national average, and mean scores on USMLE Step 2 CK for RPLP students have typically been above the national average. To reiterate, RPLP students complete the identical UKCOM preclinical curriculum (USMLE Step 1), but complete their clinical clerkship training (USMLE Step 2) in Morehead.

Table 3. Matriculating RPLP Students: USMLE Step 1 and 2 CK Scores $(n=52)$

\begin{tabular}{|c|c|c|c|}
\hline $\begin{array}{c}\text { Year } \\
\text { Admitted }\end{array}$ & $\begin{array}{c}\text { Matriculating } \\
\text { Students }\end{array}$ & $\begin{array}{c}\text { Average } \\
\text { USMLE } \\
\text { Step 1: } \\
\text { RPLP (US) }\end{array}$ & $\begin{array}{c}\text { Average } \\
\text { USMLE } \\
\text { Step 2 (CK): } \\
\text { RPLP (US) }\end{array}$ \\
\hline 2009 & 7 & $221.9(222)$ & $241.6(233)$ \\
\hline 2010 & 7 & $219.3(222)$ & $238.3(236)$ \\
\hline 2011 & 8 & $232.3(224)$ & $241.4(238)$ \\
\hline 2012 & 9 & $227.9(227)$ & $247.4(239)$ \\
\hline 2013 & 11 & $222.3(228)$ & $239.7(240)$ \\
\hline 2014 & 10 & $222.3(229)$ & $\mathrm{n} / \mathrm{a}$ \\
\hline
\end{tabular}

Residency Selection and Specialty Choice

Thirty-three percent (39) of RPLP graduates went on to attend residencies in Kentucky - 28.2\% (11) at the University of Kentucky. Excluding the military, $67 \%$ of graduates were accepted into their first residency choice. As shown in Figure 1, 22 (56\%) of the 39 students who have matched into residency positions did so in a primary care specialty (i.e., internal medicine, family medicine, or pediatrics). At this point, only a small handful of RPLP graduates have completed residency training, however, three of the five $(60 \%)$ have currently established practices in rural Kentucky. 


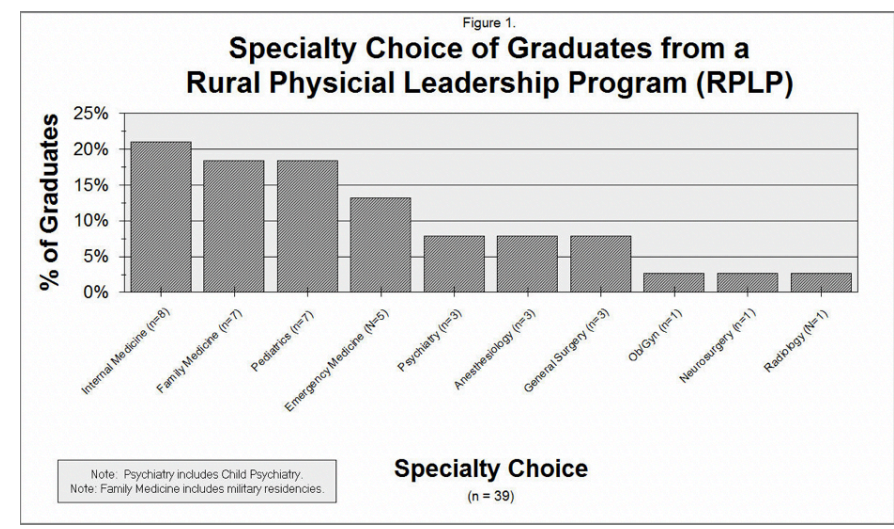

\section{Discussion}

Three factors have proven essential to a successful implementation of the University of Kentucky Rural Physician Leadership Program. First was the identification of a trusted local program champion to provide program leadership and serve as a community liaison. This individual must also understand accreditation issues and have regular communication with central campus. Second, a strong distance learning program was essential to ensuring campus comparability of educational objectives and assessments. This technology must provide lectures, interactive classrooms, small group meetings, and all other elements of M3 and M4 curricula, and students must be guaranteed dedicated local classroom and study space. Finally, regional partnerships with organizations that provide instruction and student services were also essential. The support of local clinicians enthusiastic to teach provides opportunities and mentorships that are otherwise difficult to develop. Fortunately, St. Claire Regional has a long history of clinical teaching sponsoring residencies in Pharmacy and Family Medicine - and Morehead State University had experience in providing services in support of student health, recreation, and wellness. Only through these existing strengths was the RPLP program able to leverage this expertise to successfully create and sustain a regional medical campus.

Lessons Learned

Admissions: For admission to the program, the RPLP utilizes a regional advisory committee of clinicians and other community members who were initially less familiar with the MCAT and other academic requirements for medical school admission. Thus, during the first interviews they conducted, new committee members received 'on-the job' training on academic considerations and their impact on students' potential success in medical school, a time-consuming endeavor that occasionally proved frustrating. Consequently, this onboarding process was altered so that new members now receive introductory training on the application and purpose of the advisory committee prior to interviewing. They are encouraged to review applications prior to the interview and seek clarification of any areas of concern. On the day of the interview, a guide is provided to assist each member in interpreting academic scores during the deliberation process.

Student interaction: As the first two years in the RPLP are spent on the central campus, it was soon realized that inadequate contact with students prior to their transition to the regional campus could prove detrimental. On occasions when students were struggling, either academically and personally, RPLP program staff were often unaware. In addition, moving from a large, urban AMC to a smaller rural medical center was a culture shock for some students, and several initially struggled after arriving in Morehead. The differences were also tangible: students familiar with central campus policies and processes needed to shift gears to accommodate those procedures designed to facilitate patient care in a smaller rural hospital. The clinical expectations were also unique: being a small group, learners may be the sole medical students on a service in a rural setting, necessitating their roles as being an integral part on the healthcare team.

To gauge success, the RPLP program actively monitors shelf scores, class rank, USMLE Step 1 and 2 (CK and CS) performance, as well as honors and awards received during medical school. After graduation, this surveillance extends to specialty selection, residency program, and location of eventual practice. Although a young program with only proximal outcomes, strides have been made in the development and education of future rural providers. Time will tell if the RPLP will bolster the supply of rural physicians and, ultimately, positively impact the health of rural Kentuckians. References

1. Comprehensive Statewide Physician Workforce Study. Kentucky Institute of Medicine. 2007.

2. 2010 Census Urban and Rural Classification and Urban Area Criteria. 2013.

http://www.census.gov/geo/reference/ua/urban -rural-2010.html.

3. Quality Through Collaboration: The Future of Rural Health Care. The National Academies Press. 2005.

4. Wheat, J.R., Leeper, J.D., Brandon, J.E., et al. The Rural Medical Scholars Program Study: Data to Inform Rural Health Policy. J Am Board Fam Pract. 2011;24(1):93-101.

5. Rabinowitz, H.K. Recruitment, Retention, and Follow-up of Graduates of a Program to Increase the Number of Family Physicians in Rural and Underserved Areas. N Engl J Med. 1993;328(13):934-939. 
Original Report

6. Rabinowitz, H.K., Diamond, J.J., Markham, F.W., et al. A Program to Increase the Number of Family Physicians in Rural and Underserved Areas: Impact after 22 Years. JAMA. 1999;281(3):255-260.

7. Jefferson Medical College: Physician Shortage Area Program. (2013).

http://www.jefferson.edu/jmc/psap.html. Accessed 1/31/2013.

8. Smucny, J., Beatty, P., Grant, et al. An evaluation of the Rural Medical Education Program of the State University of New York Upstate Medical University, 1990-2003. Aca Med. 2005:80(8):733-738.

9. Zink, T., Center, B., Finstad, D., et al. Efforts to Graduate More Primary Care Physicians and Physicians Who Will Practice in Rural Areas: Examining Outcomes From the University of Minnesota-Duluth and the Rural Physician Associate Program. Acad Med. 2010;85(4):599604.

10. Appalachian Regional Commission: Kentucky. 2014. from

http://www.arc.gov/appalachian_region/Kentuck y.asp

11. Chipp, C., Dewane, S., Brems, et al. "If Only Someone Had Told Me...": Lessons From Rural Providers. J Rural Health. 2011;27:122-130.

12. Hancock, C., Steinbach, A., Nesbitt, T., et al. Why doctors choose small towns: A developmental model of rural physician recruitment and retention. Soc Sci Med. 2009;69:1368-1376. 